\title{
Level of knowledge and misconceptions about brain concussion in Brazilian adults
}

\author{
Nivel de conhecimento e de equívocos sobre concussão cerebral em adultos brasileiros \\ Amanda Vitória Lacerda DE ARAÚJO', Renata AREZA-FEGYVERES', Carla Cristina GUARIGLIA', \\ Jéssica Natuline IANOF', Regina Maria BARATHO², José Luiz Carlos DEMARIO², \\ Rafael Gustavo Sato WATANABE', Renato ANGHINAH ${ }^{1}$
}

\begin{abstract}
Background: Brain concussion (BC) is seen as a public health priority due to its high incidence and morbidity rate, among thousands of people around the world. There are needs for fast identification, accurate diagnosis and correct management in order to reduce the short and long-term problems relating to BC. Proper knowledge of BC in the population and among clinicians is a critical factor in achieving this. Objectives: To evaluate the level of self-reported BC knowledge and gaps/misconceptions, and to identify variables correlated with this level. Methods: A cross-sectional descriptive survey was performed. A Brain Concussion Knowledge Questionnaire (BCKQ) that had been created to capture data was widely distributed. Total scores, domain partial scores and percentages of correct and incorrect answers were calculated to ascertain the level of knowledge relating to BC. Results: The sample was formed by 1,247 Brazilian adults (age: $41.7 \pm 11.8$ years). Partial scores of the BCKQ revealed the existence of poor knowledge and misconceptions in all domains of the questionnaire, especially regarding questions about recovery from and management of $\mathrm{BC}$. Moderate correlations between $\mathrm{BCKQ}$ scores and professions ( $p=0.312 ; P=0.00)$ or previous brain concussion knowledge $(p=0.489 ; P=0.00)$ were observed. In a multiple linear regression model, age, profession and sports practice were predictors of BC knowledge. Conclusion: This first study to analyze the level of BC knowledge in a sample of Brazilian adults suggests that poor knowledge and misconceptions are present. Thus, meaningful and useful information was provided by this study for developing health education programs about BC for the population in order to improve fast diagnosis and correct BC management.
\end{abstract}

Keywords: Brain Concussion; Cerebral Concussion; Health Care; Questionnaires.

\section{RESUMO}

Introdução: A concussão cerebral (CC) é considerada prioridade em saúde pública devido à sua alta incidência e taxa de morbidade. Há necessidade de identificação rápida, diagnóstico acurado e manejo correto após essas lesões, com objetivo de reduzir problemas de curto e longo prazo. O conhecimento apropriado da população, atletas e de clínicos é primordial para que isto seja alcançado. Objetivos: Avaliar o nível de conhecimento autorrelatado sobre CC, descrever lacunas/equívocos e identificar variáveis correlacionadas com este nível. Métodos: Foi realizada uma pesquisa descritiva transversal. O Questionário de Conhecimento sobre Concussão Cerebral (QCCC) criado foi amplamente distribuído. Pontuações totais e parciais em domínios e porcentagens de respostas corretas e incorretas foram

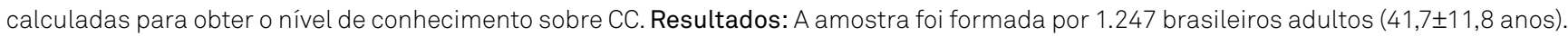
Pontuações parciais do QCCC revelaram baixo nível de conhecimento, principalmente em questões sobre recuperação e manejo. Observou-se correlações moderadas entre a pontuação no QCCC e a profissão dos participantes $(p=0,312, P=0,00)$ ou conhecimento prévio sobre $C C(p=0,489, P=0,00)$. A regressão linear múltipla mostrou que a idade, profissão e prática de esportes podem ser preditoras do conhecimento sobre CC. Conclusão: Esse primeiro estudo a analisar o nível de conhecimento sobre CC em uma amostra de adultos brasileiros sugere baixo conhecimento e equívocos sobre esta condição. Assim, informações úteis e significantes foram fornecidas para o desenvolvimento de programas de educação em saúde sobre CC para o público, com objetivo de melhorar a identificação rápida e o manejo correto de concussões.

Palavras-chave: Concussão Encefálica; Concussão Cerebral; Atenção à Saúde; Questionários.

\footnotetext{
'Universidade de São Paulo, Ambulatório de Reabilitação Cognitiva Pós-Trauma Cranioencefálico, São Paulo, SP, Brazil.

${ }^{2}$ Universidade de São Paulo, Centro Dr. Jair Minoto Abe, São Paulo SP, Brazil.

Amanda Vitória Lacerda DE ARAÚJO (D) https://orcid.org/0000-0003-2681-4240; Renata AREZA-FEGYVERES (D) https://orcid.org/0000-0003-2913-7089; Carla Cristina GUARIGLIA (D) https://orcid.org/0000-0003-2979-9330; Jéssica Natuline IANOF (D) https://orcid.org/0000-0002-8720-6137; Regina Maria BARATHO (D) https://orcid.org/0000-0001-8743-1740; José Luiz Carlos DEMARIO (iD) https://orcid.org/0000-0002-6090-7478; Rafael Gustavo Sato WATANABE (D) https://orcid.org/0000-0003-1684-573X; Renato ANGHINAH (D) https://orcid.org/0000-0001-8414-8536 Correspondence: Amanda Vitória Lacerda de Araújo; E-mail:amandavla@usp.br.

Conflict of interest: There is no conflict of interest to declare.

Authors' contributions: AVLA, RAF, CCG, and RW were responsible for designing the study and constructing the questionnaire. AVLA, RA, and RAF wrote the study and critically assessed the methodological quality. JNI interpreted the results, updated reference lists and created tables and figures. RMB and JLCD were responsible for statistical analysis.

Received on December 17, 2019; Received in its final form on July 22, 2020; Accepted on August 04, 2020.
} 


\section{INTRODUCTION}

Brain concussion (BC) is a type of mild traumatic brain injury (TBI) ${ }^{1}$. It is a complex injury that increasingly is receiving the attention of researchers. $\mathrm{BC}$ is seen as a public health priority ${ }^{2}$ due to its high incidence among contact sports play$\mathrm{ers}^{3,4}$ and the large numbers of cases in the general population ${ }^{5,6}$, which leads to morbidity in thousands of people worldwide. The United States Centers for Disease Control has estimated that the annual incidence of TBI ranges from 1.6 to 3.8 million cases, including sports-related concussion? In Brazil, Junge et al. ${ }^{8}$ showed that TBI was the second most prevalent injury in football (soccer) during the World Cup in Brazil in 2014. Thus, brain concussions are seen as a public health priority ${ }^{2}$ particularly in countries where contact sports are very common, such as football in Brazil.

A non-penetrating blunt head trauma resulting in functional transient brain disturbance may involve altered mental status, loss of consciousness and post-concussive symptoms, such as headache, dizziness, memory deficits, poor attention or irritability ${ }^{9,10}$. Therefore, $\mathrm{BC}$ is of concern because of the spectrum of potential complications relating to it.

Potential complications involve persistence of post-concussive symptoms for prolonged periods of time ( $>3$ months), and are seen in $10-15 \%$ of concussed individuals ${ }^{11,12,13}$. Prolonged post-concussive symptoms are related to impairments of quality of life ${ }^{14}$ and may lead to contact sports players' retirement ${ }^{5,14}$. Furthermore, repeated brain concussions have been associated with chronic traumatic encephalopathy in contact sports players ${ }^{14}$. This progressive tauopathy leads to deleterious effects on long-term brain functioning ${ }^{12}$. Moreover, a second impact syndrome leading to catastrophic cerebral edema and death may occur if people suffer a second impact before the first $\mathrm{BC}$ has been resolved ${ }^{15,16}$.

Because of the potential harm caused by $\mathrm{BC}$, and its incidence, there are needs for fast identification, accurate diagnosis and correct management, to reduce the short and long-term problems. Identification of $\mathrm{BC}$ depends on symptoms detected through clinical observations and patient self-reporting, or observations by witnesses ${ }^{5,10}$. Thus, proper knowledge of $\mathrm{BC}$ in the population and among sports players and clinicians is a critical factor for improving the identification, reporting and correct management of $\mathrm{BC}$ as well as reducing post-concussive sequelae, severe long-term brain function consequences, and death ${ }^{16,17}$.

Knowledge regarding $\mathrm{BC}$ in the general population has been investigated in a range of studies around the world. However, the results have suggested that knowledge or misconceptions about BC is poor among sports players clinicians, and general population ${ }^{18,19,20}$. Thus, there is a need for $\mathrm{BC}$ health education programs around the world, and efforts to implement such programs are currently underway it ${ }^{18,19,20}$. On the other hand, to the best of our knowledge, there are no Brazilian studies on the level of knowledge about BC in Brazil.
The lack of evidence about BC knowledge among Brazilians makes it difficult to develop health education programs and, consequently, to prevent BC. Thus, the current study has an important role, consisting of identifying whether there is a lack of knowledge or misconceptions about BC. Furthermore, these data should serve as a basis in the literature for developing future studies that aim to carry out health education programs to alert about the dangers of $\mathrm{BC}$.

Moreover, the present study on BC knowledge levels should highlight problems relating to access to health information and prevention of $\mathrm{BC}$ in a population in Brazil, an emerging country. This is particularly important because previous Brazilian studies showed that the estimated incidence of TBI was low $^{18}$, compared with what has been reported in studies conducted in other countries. Moreover, previous Brazilian studies found low rates of brain concussion reported (38-53\%) among TBI cases notified ${ }^{21}$, in comparison with the BC rates of $80-90 \%$ identified ${ }^{10,18}$ in other studies. Lower incidence and notification rates could be related to poor $\mathrm{BC}$ knowledge in the population and, therefore, problems with case identification, thus leading to unreported hospital notifications. Thus, based on previous data ${ }^{10,22}$, prevention of potentially serious short and long-term consequences relating to $\mathrm{BC}$ could be impaired by poor knowledge.

Hence, there is a critical need to develop research evaluating the Brazilian population's BC knowledge in order to identify problems or misconceptions about $\mathrm{BC}$ and provide the basis for developing health education programs aimed at prevent the consequences of these shortcomings. The current cross-sectional study was performed (1) to evaluate the level of self-reported BC knowledge in a sample of Brazilian adults; (2) to describe gaps or misconceptions; and (3) to identify variables correlated with BC knowledge levels.

\section{METHODS}

In order to assess the level of $\mathrm{BC}$ knowledge in a sample of Brazilian adults, a cross-sectional descriptive survey was conducted. An online questionnaire was distributed between January and August 2018. Ethical approval was obtained from the University of São Paulo Human Research Ethics Committee; all participants provided online informed consent prior to study enrolment; and data were stored and processed anonymously.

\section{Participants}

Participants were selected through an open sampling procedure by means of clusters. Self-administered online surveys were distributed to potential participants randomly. Participants belonging to sports clubs, athletic associations, universities and schools located in São Paulo, Brazil, were recruited. Participants were considered eligible if they were males or females living in Brazil, aged over 18 years and 
native Portuguese speakers. Invitations to complete the survey were disseminated via e-mail and social media, consisting of an information form that explained the details of the study and invited participation.

\section{Survey design}

Based on a detailed review of the literature, previous surveys3,23 and feedback from two experts in the field of $\mathrm{BC}$ (RAF and RA), a pilot version of the structured 31-item Brain Concussion Knowledge Questionnaire (BCKQ) was generated and screened for mistakes. The pilot version was corrected and subsequently applied to a representative sample of Brazilians. Additional adjustments were made to produce the final version of the BCKQ.

Statements for the BCKQ were context-adapted from the previous studies ${ }^{3,23}$. Additional statements were included with a view to deepening the evaluation of concussion knowledge. The BCKQ was developed on an online platform $\left(\right.$ Google Forms ${ }^{\circledR}$ ).

An online-link survey method was used to improve the applicability of the BCKQ because this allows recruitment of a larger sample and makes it possible for individuals who would be unable to attend a face-to-face meeting, to respond to the survey from their homes ${ }^{24}$. Moreover, instant electronic data archiving makes the data collection more flexible ${ }^{25}$. The BCKQ contained written instructions, an online informed consent form and 31 items designed for self-administration.

The BCKQ was structured into three parts: a demographic section (sex, age, schooling and profession), an experiencerelated section (sports practice, $\mathrm{BC}$ history and previous concussion education) and a brain concussion knowledge section (31 items). These 31 items were divided into four specific domains: identification and causes of $\mathrm{BC}$ (six items); functional and neurological consequences of $\mathrm{BC}$ (nine items); recovery and management after $\mathrm{BC}$ (nine items); and sportsrelated $\mathrm{BC}$ (six items). Each item presents $\mathrm{BC}$ facts or misconceptions, in which the participant is able to choose between true or false alternatives. Additionally, the BCKQ has a checklist containing the fourteen most frequent $\mathrm{BC}$ signs or symptoms ${ }^{26,27}$ plus four distractor symptoms. The participants were informed that they should mark all signs/symptoms that they thought were related to BC. No definition of BC was provided for the participants, so that this would not influence the participants' responses.

All 31 BCKQ items were tabulated to create a total BC knowledge score. Each item of the specific domains was marked as either correct or incorrect. A score of one point was given for the correct answer. Total $\mathrm{BC}$ knowledge was calculated by summing the number of correct answers. The total possible BCKQ score is 48 points: this score representing $100 \%$ correct answers and, therefore, high or improved knowledge of $\mathrm{BC}$. The total score is formed by the sum of the partial scores from the domains. In the domains of identification and causes of $\mathrm{BC}$ and sports-related $\mathrm{BC}$, a score of six points is possible. In the domains of functional and neurological consequences of $\mathrm{BC}$ and recovery and management, nine points are possible. The 18-item checklist was scored with one point for each correct sign or symptom (ranging from 0 to 18).

\section{Statistical analysis}

The data were entered into a Microsoft Excel spreadsheet (v. 2010, Microsoft ${ }^{\circledR}$ ). Descriptive statistics were calculated to summarize demographics, total BCKQ score, partial scores, percentage of correct and incorrect answers and adherence rate. Normally-distributed data were described as the mean and standard deviation (SD) and non-normal data as the median and percentile. Frequency and percentile were used to describe categorical variables. Our primary outcomes were the total score found through the BCKQ survey, partial scores for each domain and percentage of correct answers. The data were then entered into, and all analyses were performed in, the SPSS software, version 21. Pearson's correlation coefficient (r) was used to examine correlations between the total BCKQ score and age. Correlations between the total BCKQ score and the variables of sex, degree of schooling, type of profession, practicing of sports, previous concussion knowledge and history of concussion were analyzed by means of Spearman's rho (p). All analyses were conducted with the significance level set at $\mathrm{p}<0.05$. Missing data were reported in the Results section and were used to calculate the adherence rate of the BCKQ. A multiple linear regression model was used to determine factors influencing the level of knowledge about $\mathrm{BC}$. The independent variables included in the regression model were age, sex, degree of schooling, type of profession and practicing of sports and its frequency.

\section{RESULTS}

The BCKQ survey was completed by 1247 Brazilian adults (mean age $41.7 \pm 11.8$ years), living in São Paulo. The demographics of the participants are listed in Table 1.

Table 2 summarizes the data on previous BC knowledge and history of BC. A total of $56 \%$ of the participants $(n=700)$ reported having previous knowledge about BC. However, a high number of people reported the alternative "I do not know or I'm not sure what brain concussion is" (44\%; $\mathrm{n}=547)$. These data highlight the absence of knowledge about $\mathrm{BC}$ in a high percentage of the sample and should be considered concerning. Participants who checked the option "I do not know or I'm not sure what brain concussion is" did not proceed to the next section of the questionnaire. Thus, the BCKQ total and partial scores are presented based on a sample of 700 participants.

Knowledge gaps and misconceptions were identified through the BCKQ total score. The mean total BCKQ score 
Table 1. Demographic characteristics of the study sample $(n=1,247)$.

\begin{tabular}{|c|c|}
\hline Demographic characteristics & Frequency (\%) \\
\hline \multicolumn{2}{|l|}{$\operatorname{Sex}(n=1,247)$} \\
\hline Female & $1048(84)$ \\
\hline Male & $199(16)$ \\
\hline \multicolumn{2}{|l|}{ Age in years $(n=1,247)$} \\
\hline$<20$ & $9(0.7)$ \\
\hline $20-29$ & $165(13.2)$ \\
\hline $30-39$ & 435 (34.9) \\
\hline $40-49$ & $313(25)$ \\
\hline $50-59$ & $210(16.8)$ \\
\hline $60-69$ & $103(8.3)$ \\
\hline$>70$ & $12(1)$ \\
\hline \multicolumn{2}{|l|}{ Education level $(n=1,247)$} \\
\hline Elementary school & $6(4.8)$ \\
\hline High school graduate & $121(9.8)$ \\
\hline Bachelor's degree or higher & $1120(89.8)$ \\
\hline \multicolumn{2}{|l|}{ Profession } \\
\hline Fields of healthcare or sports & 284 (23) \\
\hline Other areas & $963(77)$ \\
\hline \multicolumn{2}{|l|}{ Type of sports $(n=1,214)$} \\
\hline Contact sports & $61(5)$ \\
\hline Non-contact sports & 704 (58) \\
\hline None & $449(37)$ \\
\hline \multicolumn{2}{|l|}{ Level of sports practice $(n=1,239)$} \\
\hline Professional & $21(1.8)$ \\
\hline Semi-professional & $49(4)$ \\
\hline Recreational & $703(56.7)$ \\
\hline None & $466(37.6)$ \\
\hline \multicolumn{2}{|l|}{ Sports frequency } \\
\hline None & $449(36)$ \\
\hline Once every 15 days & $78(6.3)$ \\
\hline Once or twice a week & $288(23.1)$ \\
\hline Three or four times a week & $313(25.1)$ \\
\hline Five or six times a week & $69(5.5)$ \\
\hline Daily & $50(4)$ \\
\hline
\end{tabular}

was $24 \pm 10.3$ points, corresponding to a correct-answer rate of $50 \%$. Thus, poor BC knowledge was observed. Based on the partial scores for each domain, specific larger gaps or misconceptions could be seen in the domain of recovery and management after $\mathrm{BC}$, with the lowest mean score (3.5 \pm 1.8 points) and lowest rate of correct answers (38\%) (Figure 1). However, all the domains had low scores. The mean score in the domains of identification and causes of BC (3.5 \pm 1.5 points) and functional and neurological consequences of $\mathrm{BC}(5 \pm 2$ points) represented correct-answer
Table 2. Information on previous knowledge of concussion or history of concussion ( $n=1,247)$.

\begin{tabular}{lr}
\hline $\begin{array}{l}\text { Questions and alternatives } \\
\text { Have you heard of concussion? }(n=1,247)\end{array}$ & $\begin{array}{c}\text { Frequency } \\
(\%)\end{array}$ \\
Yes & $701(56)$ \\
No & $546(44)$ \\
What is your source of knowledge about concussion? $(n=1,014)$ \\
Healthcare professional & $268(38)$ \\
Television, newspaper or magazine & $272(39)$ \\
Internet & $189(27)$ \\
Coach or team coach & $25(4)$ \\
Congress, conference or scientific meeting & $51(7)$ \\
Others & $209(30)$
\end{tabular}

Have you ever had concussion or do you live with someone who has had concussion? $\left(n=1,365^{\star}\right)$

I have never had concussion

$635(51)$

Yes, I have already had concussion

Yes, I have a family member or friend who had concussion

I do not know or am not sure what concussion is $542(44)$

Not available

*Question with multiple possible answers.

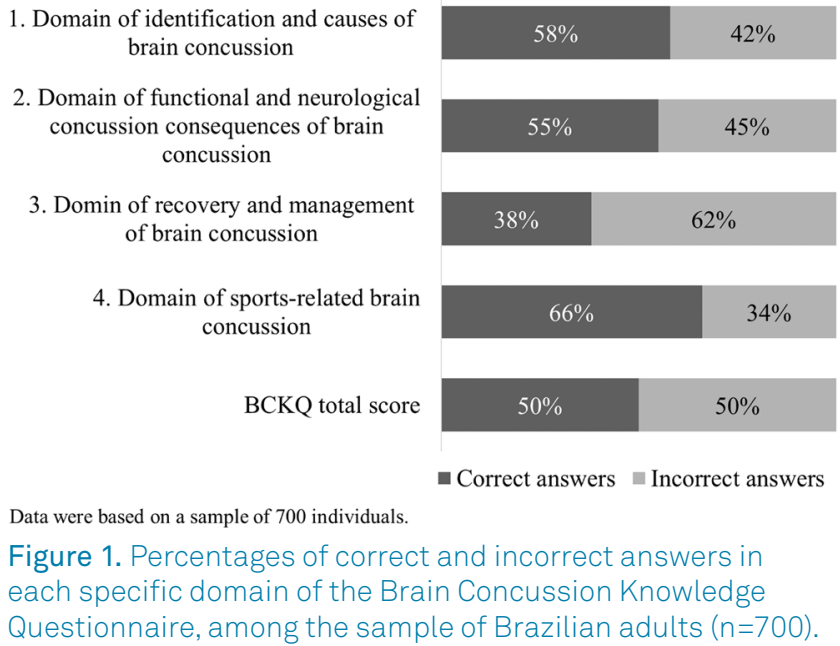

rates of 58 and $55 \%$, respectively. The domain of sportsrelated $\mathrm{BC}$ had a mean score of $4 \pm 1.4$ points and a correctanswer rate of $66 \%$.

In the question about the main signs or symptoms of $\mathrm{BC}$, the participants' mean score for the 18-item checklist was $7 \pm 3.3$ points, corresponding to a correct-answer rate of $38 \%$. Figure 2 shows the percentage of correct and incorrect answers. Anxiety (13\%), depression (15\%), noise intolerance (21\%), light intolerance (26\%) and sleep disturbance (34\%) had the lowest rates of correct answers (Figure 2). 


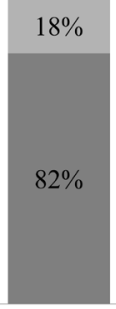

Headache

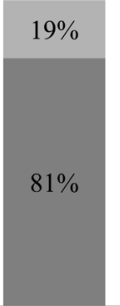

Dizziness

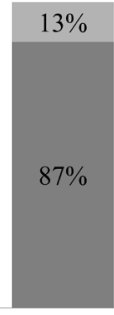

Impaired conciousness

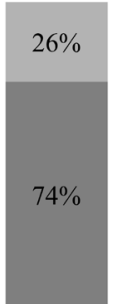

Blurred Blurred
vision

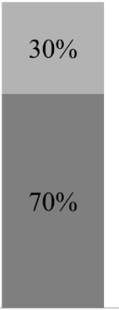

Amnesia

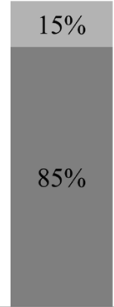

Confusion

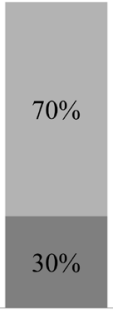

Light intolerance

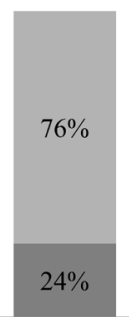

Noise Noise
ntolerance

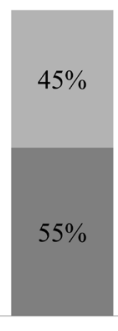

Motor disorder

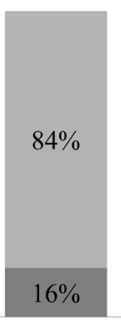

Depression

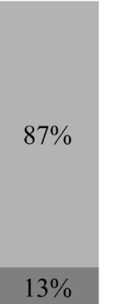

Anxiety

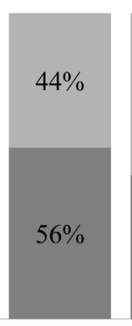
deficit

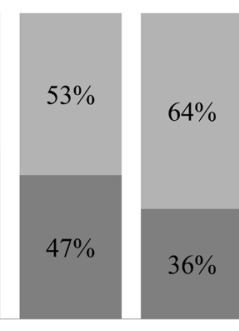

deficit disturbance

Data were based on a sample of 700 individuals.

Figure 2. Percentages of signs and symptoms most commonly correlated with brain concussion, according to the responses

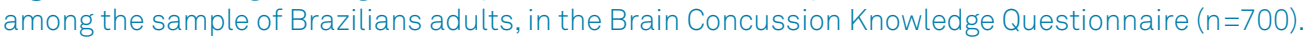

Table 3 show detailed information about the percentages of the answers to each BCKQ statement. Alarming gaps and misconceptions were observed. There was a high rate of incorrect answers (87\%) to the statement "the only way to be sure that a person has suffered brain damage from a concussion is by cranial tomography or magnetic resonance imaging of the skull". Sixty-five percent believed that "emotional problems after brain concussion are usually not related to brain damage". Similarly, $60 \%$ chose an incorrect answer when asked if "a brain concussion can make a person feel depressed, hopeless and sad". High rates of incorrect answers were also observed regarding the statements "it is easy to tell if a person has had brain damage from a concussion because of the way a person behaves" (56\%) and "most people who suffer a brain concussion do not realize the effect of the injury on their behavior and reasoning" (55\%). Also, most of the participants (69\%) did not know that "a person may die if a second brain concussion occurs before recovery from an earlier concussion". Impairment of the capacity to learn new things was also a knowledge gap for 358 of the participants (52\%).

Fifty-two percent of the participants $(n=362)$ believed that "recovery from a brain concussion does not occur". Most of the participants (91\%) also did not know that the symptoms of a brain concussion pass after 10 days. Equally, $74 \%$ of the sample $(\mathrm{n}=517)$ presented incorrect answers when asked if "sports players who had a brain concussion would be more likely to have another". Fifty-five percent $(n=385)$ thought that a sports player who had suffered a BC could continue playing if he or she felt good. Likewise, $57 \%$ of the sample believed that a "soccer player who had suffered a brain concussion could return to the next ball practice if he or she felt well".

The BCKQ adherence rate remained high for most questions, with a rate of missing answers $<1 \%$. Moderate positive correlations between BCKQ total scores and professions linked to the fields of healthcare or sports were observed $(\mathrm{p}=0.312 ; \mathrm{P}=0.00)$. Similarly, the BCKQ total score also showed a moderate positive correlation with previous $\mathrm{BC}$ knowledge $(\mathrm{p}=0.489 ; \mathrm{P}=0.00)$. Only poor correlations were found in relation to $\operatorname{sex}(\mathrm{p}=0.096 ; \mathrm{P}=0.00)$, age $(\mathrm{r}=0.2 ; \mathrm{p}=0.00)$ and degree of schooling ( $\mathrm{p}=0.106 ; \mathrm{P}=0.00)$. No correlations were observed for the other variables analyzed.

Multiple linear regression was performed on the data relating to 700 participants (Table 4). This showed that age was significantly related to the level of $\mathrm{BC}$ knowledge. Thus, for every one-year increase in age, the participants tended to have a BCKQ score that was 0.15 points lower. Type of profession, which was categorized as healthcare-related, sportsrelated or unrelated to either of the preceding categories, was also a predictor. Thus, participants in healthcare-related professions tended to have higher BCKQ scores. Participants in sports-related professions had BCKQ scores that were 7.03 points lower. This was an alarming result because sports professionals are close to individuals who are more likely to suffer a BC. Furthermore, participants who practiced sports had BCKQ scores that were 1.82 points lower than those of participants who did not. Curiously, regression analysis showed that participants who practiced sports daily had BCKQ scores that were 4.01 points lower (Table 4). Since the individuals who played sports daily in our sample were athletes, this is a worrying result. No interaction occurred between the other variables included in the model.

\section{DISCUSSION}

To the best of our knowledge, this is the first study to examine the level of $\mathrm{BC}$ knowledge among Brazilian adults. The results from this cross-sectional descriptive survey provide evidence of poor $\mathrm{BC}$ knowledge and a moderate rate of misconceptions in a sample of Brazilians with a high level of schooling. Our findings showed that a high proportion of the sample did not know what $\mathrm{BC}$ is (44\%). These data highlight the absence of knowledge about $\mathrm{BC}$ in a high percentage of the sample and should be considered concerning.

Moreover, there was poor knowledge in all BCKQ domains, i.e., the participants had impaired knowledge of how to identify a $\mathrm{BC}$ and what causes it, the functional and neurological consequences of $\mathrm{BC}$, the recovery and correct management 
Table 3. Knowledge gaps identified for each statement in specific domains of the Brain Concussion Knowledge Questionnaire, according to the answers of the Brazilian sample $(n=700)$.

$\operatorname{BCKQ}(n=700)$

Statements (correct answer)

\section{Frequency (\%)}

True

False

NA

Domain of identification and causes of brain concussion

1. Brain concussion can cause brain damage even if the person has not fainted (T)

$580(82) \quad 120(18) \quad 0$

2. A person needs to have passed out to be diagnosed with brain concussion (F)

3. The only way to tell whether someone has suffered brain damage from concussion is by mean of cranial tomography or magnetic resonance imaging $(F)$

4. Brain concussion can only occur if there is a direct hit to the head (F)

5. An impact on the body that causes rapid acceleration and deceleration of the head can cause brain damage even if there is no direct blow to the head $(T)$

6. It is easy to tell whether a person has brain damage from concussion from the way the person looks or behaves (F)

Domain of functional and neurological consequences of brain concussion

7. Brain concussion is harmless and never results in long-term problems or brain damage (F)

8. A little brain damage does not matter, as people only use a small part of their brains anyway (F)

9. Most people who suffer brain concussion do not realize the effect of concussion on their behavior and reasoning $(T)$

10. A person may die if a second brain concussion occurs before recovery from a previous one (T)

11. Brain concussion can make a person feel depressed, hopeless and sad (T)

12. Emotional problems after brain concussion are usually not related to brain damage (F)

13. A person who has suffered brain concussion may have trouble recalling facts before the concussion $(T)$

14. Multiple concussions over the course of life can give rise to brain problems (T)

15. A person who has suffered brain concussion may have trouble learning new things $(T)$

Domain of recovery and management of brain concussion

16. Sometimes a second blow to the head can help a person remember things that were forgotten (F)

17. Once a recovering person feels normal, the recovery process is complete (F)

18. Complete recovery from brain concussion is not possible, no matter how badly the person wants to recover $(F)$

19. How quickly a person recovers from brain concussion depends mainly on how hard they work on recovery $(F)$

20. It is recommended to rest and remain inactive during recovery from brain concussion (F)

21. After 10 days the symptoms of brain concussion are usually completely gone (T)

22. A person who has not recovered from brain concussion is less able to withstand a second blow to the head $(T)$

23. The most appropriate way to evaluate the progress of recovery after brain concussion is by asking the person who was concussed how they feel $(T)$

24. Most people wake up quickly and undamaged after being knocked unconscious by a blow to the head $(T)$

Domain of sports-related brain concussion

25. In sports, brain concussion rarely happens (F)

26. Athletes who have had one brain concussion are more susceptible to having another (T)

27. Athletes who practice contact sports are at greater risk of brain concussion (T)

28. A soccer player who has suffered brain concussion may continue to play as long as they feels $\operatorname{good}(F)$

29. A soccer player who has suffered brain concussion during a workout can return to the next ball practice as long as they feel good (F)

30. A soccer player who felt dizzy after suffering brain concussion and returned to dizziness when training should continue training until the dizziness improves $(F)$

BCKQ: Brain Concussion Knowledge Questionnaire; F: false; T: true.
$154(23) \quad 544(77) \quad 2$

$608(87)^{*} \quad 91(13) \quad 1$

$233(34) \quad 465(66) \quad 2$

$528(75) \quad 172(25) \quad 0$

$391(56)^{*} \quad 309(44) \quad 0$

$196(28) \quad 504(72) \quad 0$

$92(13) \quad 607(87) \quad 1$

$310(45) \quad 388(55)$ * 2

$223(41) \quad 473(69) * \quad 4$

$278(40) \quad 422(60)^{*} 0$

$453(65) * 245(35) \quad 2$

$547(78) \quad 151(22) \quad 2$

$518(74) \quad 180(26) \quad 2$

$330(48) \quad 368(52)$ * 2

$273(40) \quad 425(60) \quad 2$

$197(29) \quad 501(71) \quad 2$

$362(52) * 337(48)$

$374(54) * \quad 324(46)$

$521(76) * \quad 178(24)$

$65(8) \quad 634(91) * 1$

$297(42) \quad 402(58)$ * 1

$101(14) 596(86)^{*} 3$

$165(24) \quad 531(76)^{*} 4$

$70(10) \quad 628(90) \quad 2$

$178(26) \quad 517(74) * 5$

$560(80) \quad 137(20) \quad 3$

$385(55)^{*} \quad 313(45) \quad 2$

$401(57) * \quad 295(43) \quad 4$

$173(25) \quad 523(75) \quad 4$ 
Table 4. Multiple linear regression model to predict variables relating to brain concussion knowledge $(n=700)$.

\begin{tabular}{lccc}
\hline Variables & Estimate & SE & p-value \\
\hline Age (years) & -0.15 & 0.03 & $<0.001^{*}$ \\
Sex (female) & 1.20 & 0.93 & 0.195 \\
\hline Profession & & & \\
$\quad$ Healthcare (reference category) & 1.00 & - & - \\
Sports-related & -7.03 & 2.37 & $0.003^{*}$ \\
Not related to healthcare & -7.32 & 0.84 & $<0.001^{\star}$ \\
or sports & & & \\
Degree of schooling & & & \\
$\quad$ Elementary school & 1.00 & - & - \\
(reference category) & 6.19 & 6.95 & 0.373 \\
High school graduate & 6.59 & 6.85 & 0.336 \\
Bachelor's degree or higher & 1.82 & 0.78 & $0.021^{*}$ \\
Sport practice (yes) & & & \\
\hline Sports frequency & 1.00 & - & - \\
None (reference category) & -1.58 & 1.55 & 0.309 \\
Once every 15 days & -1.84 & 0.97 & 0.058 \\
Once or twice a week & -1.70 & 0.98 & 0.084 \\
Three or four times a week & -1.00 & 1.68 & 0.551 \\
Five or six times a week & -4.01 & 1.92 & $0.037 *$ \\
\hline Daily & & &
\end{tabular}

SE: standard error; ${ }^{*} \mathrm{p}<0.05$.

after BC and the recovery after sports-related BC. These findings are supported by the fact that many of the participants stated that they did not know what a BC is. On the other hand, a proportion of the participants stated that they had previous $\mathrm{BC}$ knowledge from healthcare professionals, the internet or television, newspapers or magazines. Thus, our findings show that when the participants had previous $\mathrm{BC}$ information, the transfer of knowledge may have been impaired, thus resulting in gaps or misconceptions. Furthermore, an additional concern was noted through multiple linear regression, considering that playing sports daily and having sports-related professions were predictive variables for lower scores in the BCKQ.

\section{Brain concussion knowledge}

The $\mathrm{BC}$ knowledge scores varied depending on the BCKQ domain. For instance, there was a higher number of incorrect answers in relation to statements about recovery and management after BC. This finding is worrying because a lack of adequate management and recovery may expose people to more serious consequences, such as post-concussion syndrome9,10, chronic traumatic encephalopathy15 or second impact syndrome16. To prevent the range of potential consequences of a $\mathrm{BC}$, the Brazilian population needs to become familiar with the various aspects of $\mathrm{BC}$ management and recovery. Previous studies also found that there was limited knowledge regarding the recovery and management of people with $\mathrm{BC}^{3,28}$.
Similarly, a high number of incorrect answers were observed regarding common signs or symptoms of BC. In our study, people had higher knowledge of post-concussive symptoms such as confusion, headache, impaired consciousness, dizziness, blurred vision and amnesia. However, there were very low numbers of correct answers in relation to behavioral symptoms, light or noise intolerance and sleep disturbance. Previous studies also showed limited knowledge regarding post-concussive symptoms in the general population ${ }^{29,30}$. Light or noise intolerance was also poorly identified in a study by Knollman-Potter et al. ${ }^{31}$. Data from Waltzman et al. ${ }^{32}$ showed that a small portion of their participants correctly chose sleep disturbance as a common post-concussive symptom. In agreement with our findings, studies have demonstrated that people tend to be familiar with certain BC symptoms, such as headache, dizziness and impaired consciousness ${ }^{33,34}$. Behavioral symptoms are less correlated to a $\mathrm{BC}$ by the general population ${ }^{31}$.

Overall, previous studies identified poor levels of BC knowledge in various aspects such as post-concussive symptoms, identification, recovery and management after the $\mathrm{BC}^{3,17,19,20,34,35}$. For example, McKinlay et al. ${ }^{21}$ reported that there was significant uncertainty in the general population about what a $\mathrm{BC}$ is and how it should be managed. Other studies also reported these findings ${ }^{29,32}$. Our results were generally consistent with these previous studies.

Interestingly, the first international study ${ }^{36}$ about $\mathrm{BC}$ knowledge showed that a significant proportion of their sample believed that a second blow to the head could help memory recover, which also was shown in our study. A recent study showed that the proportion of people who considered this statement correct was only $10 \%^{3}$. Our results in this regard are only concordant with those of a study conducted in 1988. Thus, there is concern about this information, and it highlights the significant breadth of misconceptions found in our study.

Other specific findings from previous studies are concordant with our results. One study ${ }^{3}$ showed that a high number of participants rejected the statement regarding the increased likelihood of a second blow to the head in sports. The percentage of incorrect answers to this statement was also high in our study. Similarly, these authors ${ }^{3}$ indicated that a substantial number of participants considered that the most appropriate way to evaluate the recovery would be to ask individuals who had become concussed how they felt. The same was observed in our sample. In comparing our findings with those of the study by Weber and Edwards ${ }^{3}$, on which our questionnaire was based, the level of $\mathrm{BC}$ knowledge in our sample was significantly lower. Thus, our data support the data in the current literature and show that Brazilian adults with high schooling levels had poor knowledge about BC. These findings highlight the urgency of health education regarding $\mathrm{BC}$ in Brazil. Studies have indicated that implementation of health education programs for the general population have led to gains in knowledge regarding the symptoms of BC, identification of this condition and correct recovery from it ${ }^{18,37,38}$. 
Improvements of knowledge about BC in the general population may increase the frequency of symptom reporting and demands for treatment ${ }^{39}$, as well as helping to prevent a range of complications and sequelae ${ }^{18}$ relating to $\mathrm{BC}$. In the light of the results from these previous studies, an increasing number of health education programs aimed at various sectors of the population have emerged in other countries ${ }^{18,37,38,39}$. Unfortunately, this scenario has not been observed in Brazil.

Hence, the current study highlights the need for an approach to health education for the general population regarding prevention of $\mathrm{BC}$, which would reduce the potentially serious short and long-term consequences of this injury. The results highlight evidence of poor knowledge and misconceptions about $\mathrm{BC}$, which may be related to impaired prevention plus a high rate of unreported $\mathrm{BC}$ at healthcare services in Brazil ${ }^{10,18}$. Furthermore, our results serve as a basis for developing future studies that aim to develop health education programs for the general population or to investigate specific aspects of the poor knowledge and misconceptions found in this study.

Regarding health education programs aimed at the general population, previous studies have shown that as more information about the etiology, management and sequelae of $\mathrm{BC}$ has emerged, awareness about the importance of safe concussion management has improved ${ }^{17,18,31,37,38,39}$. This has been demonstrated through improvements in some concussion-related knowledge over time38. Thus, understanding the knowledge gaps and misconceptions contributes to formulating strategies that are needed to specifically address these problems ${ }^{29}$.

Education programs should ideally promote active engagement of patients and improve the ability to apply previous healthcare knowledge in situations of everyday life ${ }^{31}$. The approaches used need to include multiple parts of society, such as the general community, parents, caregivers, athletes and healthcare professionals ${ }^{39}$. Furthermore, dissemination of information should include government resources, campaigns and structured programs within public healthcare services $^{31}$. To educate the general population about $\mathrm{BC}$, the educational methods and materials used should be focused on websites, flyers or lectures ${ }^{17,31,39}$. However, before
BC education programs are established, studies should be conducted to ascertain the most effective means of disseminating information to the general population.

\section{Study limitations and future research}

There are several limitations to this study. First, despite the authors' attempt to obtain a diversified sample of Brazilian adults, the final sample was composed of a higher number of females, people with high schooling levels and non-athletes. This sample composition may limit the ability to generalize the results from our study. Second, use of an online survey to reach a wider range of participants may introduce the inability to verify whether participants answered the questions without help from other sources of knowledge.

For future research, the aim should be to have a probabilistic sample that is also homogeneous, i.e., with a balance of factors such as sex, age, profession, socioeconomic status, education level and exercise practice level. Moreover, studies using interviews, comprehensive methodologies, qualitative research or open-ended questions may help to understand patterns of responses, difficulties in interpretation or misconceptions of understanding of the survey. Larger studies aiming to ascertain the variables that influence knowledge of concussion should be conducted. In addition, future studies investigating the effectiveness of using health education programs about BC are strongly recommended.

In conclusion, in this first study to examine the level of $\mathrm{BC}$ knowledge among Brazilian adults, the findings showed that BC knowledge was poor. This mirrors previous studies. Our study provided very useful information about BC knowledge among Brazilian adults and demonstrated the need for health education programs about BC. Health education programs can improve the knowledge of the population and should help to increase rapid identification and correct management of BC. Larger-scale research is needed to investigate the $\mathrm{BC}$ knowledge among groups of Brazilians such as healthcare and sports professionals. Variables that influence BC knowledge should be investigated in larger samples in order to understand what the main focus of health educational programs should be.

\section{References}

1. Kutcher JS, Giza CC. Sports concussion diagnosis and management. Continuum (Minneap Minn). 2014 Dec;20(6 Sports Neurology):1552-69. https://doi.org/10.1212/01. CON.0000458974.78766.58

2. Jackson WT, Starling AJ. Concussion evaluation and management. Med Clin North Am. 2019 Mar;103(2):251-61. https://doi. org/10.1016/j.mcna.2018.10.005

3. Weber M, Edwards MG. Sports concussion knowledge in the UK general public. Arch Clin Neuropsychol. 2012 May;27(3):355-61. https://doi.org/10.1093/arclin/acs029

4. Finch CF, McCrory P, Ewing MT, Sullivan SJ. Concussion guidelines need to move from only expert content to also include implementation and dissemination strategies. Br J Sports Med. 2013 Jan;47(1):12-4. https://doi.org/10.1136/bjsports-2012-091796

5. Voss JD, Connolly J, Schwab KA, Scher Al. Update on the epidemiology of concussion/mild traumatic brain injury. Curr Pain Headache Rep. 2015 Jul;19(7):32. https://doi.org/10.1007/s11916-015-0506-z

6. Roozenbeek B, Maas Al, Menon DK. Changing patterns in the epidemiology of traumatic brain injury. Nat Rev Neurol. 2013 Apr;9(4):231-6. https://doi.org/10.1038/nrneurol.2013.22

7. Capizzi A, Woo J, Verduzco-Gutierrez M. Traumatic brain injury: an overview of epidemiology, pathophysiology, and medical management. Med Clin North Am. 2020 Mar;104(2):213-8. https:// doi.org/10.1016/j.mena.2019.11.001 
8. Junge A, Dvorak J, Graf-Baumann T. Football injuries during the World Cup 2002. Am J Sports Med. 2004 Jan-Feb;32(1 Suppl):23S7S. https://doi.org/10.1177/0363546503261246

9. McCrory P, Meeuwisse WH, Aubry M, Cantu RC, DvořákJ, Echemendia RJ, et al. Consensus statement on concussion in sport: the 4th international conference on concussion in sport, Zurich, November 2012.J Athl Train. 2013 Jul-Aug;48(4):554-75. https://doi. org/10.4085/1062-6050-48.4.05

10. Kerr ZY, Zuckerman SL, Wasserman EB, Vegt CBV, Yengo-Kahn A, Buckley TA, et al. Factors associated with post-concussion syndrome in high school student-athletes. J Sci Med Sport. 2018 May;21(5):447-52. https://doi.org/10.1016/j.jsams.2017.08.025

11. Ahman S, Saveman BI, Styrke J, Björnstig U, Stålnacke BM. Longterm follow-up of patients with mild traumatic brain injury: a mixedmethods study. J Rehabil Med. 2013 Sep;45(8):758-64. https://doi. org/10.2340/16501977-1182

12. Silverberg ND, Iverson GL. Etiology of the post-concussion syndrome: physiogenesis and psychogenesis revisited. NeuroRehabilitation. 2011;29(4):317-29. https://doi.org/10.3233/NRE-2011-0708

13. van Eijck MM, Schoonman GG, Naalt JVD, Vries J, Roks G. Diffuse axonal injury after traumatic brain injury is a prognostic factor for functional outcome: a systematic review and meta-analysis. Brain Inj. 2018;32(4):395-402. https://doi.org/10.1080/02699052.2018.1429018

14. Concannon LG, Kaufman MS, Herring SA. The million-dollar question: when should an athlete retire after concussion? Curr Sports Med Rep. Nov-Dec 2014;13(6):365-9. https://doi.org/10.1249/ JSR.0000000000000098

15. Ling H, Morris HR, Neal JW, Lees AJ, Hardy J, Holton JL, et al. Mixed pathologies including chronic traumatic encephalopathy account for dementia in retired association football (soccer) players. Acta Neuropathol. 2017 Mar;133(3):337-52. https://doi.org/10.1007/ s00401-017-1680-3

16. McLendon LA, Kralik SF, Grayson PA, Golomb MR. The controversial second impact syndrome: a review of the literature. Pediatr Neurol. 2016 Sep;62:9-17.https://doi.org/10.1016/j.pediatrneurol.2016.03.009

17. Schellinger SK, Munson B, Kennedy MRT. Public perceptions of traumatic brain injury: predictors of knowledge and the effects of education. Brain Inj. 2018;32(11):1377-85. https://doi.org/10.1080/0 2699052.2018.1492737

18. Costa B, Sousa Filho JL, Dourado JC, Gontijo JAM, Dellaretti MA, Costa BS. Traumatic Brain Injury Epidemiology in Brazil. World Neurosurg. 2016 Mar;87:540-7. https://doi.org/10.1016/j.wneu.2015.10.020

19. Taylor ME, Sanner JE. The relationship between concussion knowledge and the high school athlete's intention to report traumatic brain injury symptoms. J Sch Nurs. 2017 Feb;33(1):73-81. https://doi. org/10.1177/1059840515619683

20. Mckinlay A, Bishop A. Mclellan T. Public knowledge of 'concussion' and the different terminology used to communicate about mild traumatic brain injury (MTBI). Brain Inj. 2011;25(7-8):761-6. https:// doi.org/10.3109/02699052.2011.579935

21. Melo JRT, Silva RA, Moreira-Junior ED. Characteristics of patients with traumatic brain injury in the city of Salvador, Bahia, Brazil. Ara Neuro-Psiquiatr. 2004;62(3A):711-5. https://doi.org/10.1590/S0004282X2004000400027

22. Melo JRT, Oliveira-Filho J, Silva RA, Moreira-Junior ED. Prognostic factors about mortality and lethality in head injury. Arq NeuroPsiquiatr. 2006;63(4):1054-7. https://doi.org/10.1590/S0004282X2005000600026

23. Rosenbaum AM, Arnett PA. The development of a survey to examine knowledge about and attitudes toward concussion in high-school students. J Clin Exp Neuropsychol. 2010 Jan;32(1):44-55. https://doi. org/10.1080/13803390902806535
24. Wright KB. Researching internet-based populations: Advantages and disadvantages of online survey research, online questionnaire authoring software packages, and web survey services. J Comput-Mediat Comm. 2005;10(3):00. https://doi. org/10.1111/j.1083-6101.2005.tb00259.x

25. Buchanan EA, Hvizdak EE. Online survey tools: Ethical and methodological concerns of human research ethics committees. J Empir Res Hum Res Ethics. 2009 Jun;4(2):37-48. https://doi. org/10.1525/jer.2009.4.2.37

26. Makdissi M, Darby D, Maruff P, Ugoni A, Brukner P, McCrory PR. Natural history of concussion in sport: markers of severity and implications for management. Am J Sports Med. 2010 Mar;38(3):464-71. https://doi.org/10.1177/0363546509349491

27. Meehan WP, D'Hemecourt P, Comstock RD. High school concussions in the 2008-2009 academic year: mechanism, symptoms, and management. Am J Sports Med. 2010 Dec;38(12): 2405-9. https://doi. org/10.1177/0363546510376737

28. Griffin AS, Ranson C, Moore I, Mathema P. Concussion knowledge and experience among Welsh amateur rugby union coaches and referees. BMJ OpenSport Exerc Med. 2017 Sep;3(1):e000174. https://doi. org/10.1136/bmjsem-2016-000174

29. Mulhern S, McMillan TM. Knowledge and expectation of postconcussion symptoms in the general population.J Psychosom Res. 2006 Oct;61(4):439-45. https://doi.org/10.1016/j. jpsychores.2006.03.004

30. King D, Brughelli M, Hume P, Gissane C. Assessment, management and knowledge of sport-related concussion: systematic review. Sports Med. 2014 Apr;44(4):449-71. https://doi.org/10.1007/s40279013-0134-x

31. Knollman-Porter K, Brown J, Flynn M. A preliminary examination of concussion knowledge by collegiate athletes and non-athletes. Am J Speech Lang Pathol. 2018 May;27(2):778-95. https://doi. org/10.1044/2018_AJSLP-17-0108

32. Waltzman D, Daugherty J. Concussion knowledge and experience among a sample of American adults. J Concussion. 2018 Jan;2:1-11. https://doi.org/10.1177/2059700218769218

33. Cournoyer J, Tripp BL. Concussion knowledge in high school football players. J Athl Train. 2014 Sep-Oct;49(5):654-8. https://doi. org/10.4085/1062-6050-49.3.34

34. Mannings C, Kalynych C, Joseph MM, Smotherman C, Kraemer DF. Knowledge assessment of sports-related concussion among parents of children aged 5 years to 15 years enrolled in recreational tackle football. J Trauma Acute Care Surg. 2014 Sep;77(3 Suppl 1):S18-22. https://doi.org/10.1097/TA.0000000000000371

35. Chow R, Hollenberg D, Ng W, Pinto D. High incidence of concussion, but low knowledge levels among young adults. Int J Adolesc Med Health. 2018 Sep;32(6). https://doi.org/10.1515/ijamh-2018-0003

36. Gouvier WD, Prestholdt PH, Warner MS. A survey of common misconceptions about head injury and recovery. Arch Clin Neuropsychol. 1988;3(4):331-43.

37. Sullivan L, Pursell L, Molcho M. Evaluation of a theory-based concussion education program for secondary school studentathletes in Ireland. Health Educ Res. 2018 Dec;33(6):492-504. https://doi.org/10.1093/her/cyy034

38. Eagles ME, Bradbury-Squires DJ, Powell MF, Maroun FB. The Impact of a Concussion-U Educational Program on Knowledge of and Attitudes about Concussion. Can J Neurol Sci. 2016 Sep;43(5):65964. https://doi.org/10.1017/cjn.2016.263

39. Register-MihalikJK, Williams RM, Marshall SW, Murphy JR, Campbell GC, Guskiewicz KM, et al. Demographic, Parental, and Personal Factors and Youth Aug;53(8):768-75. https://doi. org/10.4085/1062-6050-223-17 